\title{
Coagulant effects of black snake (Pseudechis spp.) venoms and in vitro efficacy of commercial antivenom
}

\author{
J. Lane ${ }^{\mathrm{a}, \mathrm{b}}$, M.A. O'Leary ${ }^{\mathrm{c}}$, G.K. Isbister ${ }^{\mathrm{b}, \mathrm{c}, *}$ \\ ${ }^{a}$ Faculty of Medical Sciences, Newcastle University, Newcastle upon Tyne, United Kingdom \\ ${ }^{\mathrm{b}}$ Discipline of Clinical Pharmacology, University of Newcastle, NSW, Australia \\ ${ }^{\mathrm{c}}$ Department of Clinical Toxicology and Pharmacology, Calvary Mater Newcastle, Newcastle, NSW, Australia
}

\section{A R T I C L E I N F O}

\section{Article history:}

Received 16 March 2011

Received in revised form 29 May 2011

Accepted 31 May 2011

Available online 23 June 2011

\section{Keywords:}

Pseudechis

Venom

Coagulopathy

Anticoagulation

Phospholipase A2

\begin{abstract}
A B S T R A C T
The coagulant effects of Australasian black snakes (Pseudechis spp.) are poorly understood and differ to the procoagulant venoms of most dangerous snakes in Australia. This study aimed to investigate in vitro coagulant effects of Pseudechis venoms and the efficacy of commercial black snake antivenom (BISAV), tiger snake antivenom (TSAV) and specific rabbit anti-snake IgG to neutralise these effects. Using a turbidimetric assay, all six Pseudechis venoms had anticoagulant activity, as well as phospholipase $\mathrm{A}_{2}\left(\mathrm{PLA}_{2}\right)$ activity. Inhibition of PLA $\mathrm{P}_{2}$ activity removed anticoagulant effects of the venoms. Pseudechis porphyriacus was unique and had procoagulant activity independent of PLA2 activity. Both BISAV and TSAV completely inhibited the coagulant and PLA2 activity of all Pseudechis venoms. PLA2 activity was also inhibited completely by p-Bromophenacyl bromide (pBPB) and partially by specific anti-N. scutatus IgG antibodies. Anti-N. scutatus IgG also completely inhibited anticoagulant activity of Pseudechis venom. All Pseudechis venoms showed immunological cross reactivity with specific anti-snake IgG antibodies to P. porphyriacus, Pseudechis australis and Notechis scutatus. Pseudechis venoms have in vitro anticoagulant activity that appears to be attributable to PLA 2 activity. Both antivenoms inhibited anticoagulant and $\mathrm{PLA}_{2}$ activity at concentrations below those occurring in patients treated with one vial of antivenom. There was cross-neutralisation of Pseudechis venoms and $N$. scutatus antibodies that might be attributable to immunological similarities between the venoms.
\end{abstract}

Crown Copyright $\odot 2011$ Published by Elsevier Ltd. All rights reserved.

\section{Introduction}

The Pseudechis genus (black snakes) is one of five groups of clinically important venomous snakes in Australia (White, 1998). Pseudechis spp. are widespread across Australia. The two most common and clinically significant black snakes, Pseudechis porphyriacus (Red-bellied black snake) and Pseudechis australis (Mulga snake) are found

\footnotetext{
* Corresponding author. Calvary Mater Newcastle, Edith St, Waratah NSW 2298, Australia. Tel.: +612 4921 1211; fax: +612 49211870.

E-mail address: geoff.isbister@gmail.com (G.K. Isbister).
}

along the East Coast of Australia and throughout mainland Australia respectively (Cogger, 2000). Other members of the genus include Pseudechis butleri (Butler's snake), Pseudechis colletti (Collett's snake), Pseudechis guttatus (Spotted or blue-bellied black snake) and Pseudechis papuanus (Papuan black snake) which are less widespread in Australasia and cause far fewer bites (Isbister et al., 2006; Jansen et al., 2007).

The majority of medically important venomous Australian snakes cause a venom induced consumptive coagulopathy (VICC) that results in clotting factor deficiencies and the risk of bleeding (Isbister, 2006; Isbister et al., 2010a, b). This is not the case with Pseudechis spp. 
which cause a reversible anticoagulant coagulopathy (Campbell, 1984; Isbister et al., 2006; Churchman et al., 2010). However, despite extensive investigation of procoagulant toxins in Australasian elapids (Isbister, 2009) there has been limited study of the anticoagulant toxins (Madaras et al., 1983). Anticoagulant toxins have been identified in other snake venoms and many of these have been identified as phospholipase $\mathrm{A}_{2}\left(\mathrm{PLA}_{2}\right.$ ) enzymes (Kini, 2006). $P_{2} A_{2}$ enzymes are present in many animals including humans and serve many biological functions. Snake venoms $\mathrm{PLA}_{2}$ have a toxic activity (e.g. myotoxic, anticoagulant, neurotoxic) in addition to their enzymatic activity and these functions may or may not be independent (Lomonte et al., 2003; Kini, 2006). PLA 2 toxins including myotoxins, platelet inhibitors and anticoagulant toxins have been identified in some Pseudechis spp. but a comprehensive study of anticoagulant activity of Pseudechis venoms and whether this is associated with $\mathrm{PLA}_{2}$ activity has not been undertaken (Kamiguti et al., 1994; Laing et al., 1995; Ramasamy et al., 2004; Kini, 2006).

The current clinical knowledge regarding envenoming by black snakes comes mainly from case reports and anecdotes. Effects of envenoming include systemic symptoms, myotoxicity, anticoagulant coagulopathy, and localised effects at the bite site which rarely result in necrosis (Vines, 1978; Campbell, 1984; Lalloo et al., 1994; Pearn et al., 2000; Currie, 2004; Isbister et al., 2006; Jansen et al., 2007; Churchman et al., 2010). Myotoxicity appears to be the most important clinical effect and may result in acute renal failure in some cases. The presence and importance of an anticoagulant coagulopathy is more contentious with mixed reports of its presence. From a recent large series of Pseudechis porphyriacus envenoming anticoagulant coagulopathy appears to be common, occurring in $61 \%$ of patients, and was characterised by a raised activated partial thromboplastin time (aPTT). This anticoagulant coagulopathy was rapidly reversed with administration of one vial of antivenom (Churchman et al., 2010). It is therefore important to characterise the coagulant effects of Pseudechis venoms, both anticoagulant and procoagulant, including the efficacy of antivenoms in neutralising these coagulant effects.

This study aimed to investigate the anticoagulant and procoagulant effects of Pseudechis venoms for a range of venom concentrations including those found in patients with envenoming. In addition it investigated the effects of black snake antivenom (BISAV) and tiger snake antivenom (TSAV) on the anticoagulant effects.

\section{Materials and methods}

\subsection{Venom and antivenom preparation}

P. porphyriacus, P. australis, Notechis scutatus (Tiger snake) and Oxyuranus scutellatus (Taipan) venoms were obtained from Venom Supplies. P. butleri, P. colletti, $P$. guttatus and $P$. papuanus venoms were gifted by Monash Venom Group. Venom solutions were made to $1.0 \mathrm{mg} / \mathrm{ml}$ in $50 \%$ glycerol and stored at $-20{ }^{\circ} \mathrm{C}$ until required.

CSL tiger snake antivenom (TSAV; batch 10402, expiry October 2008) and black snake antivenom (BISAV; batch
07301; expiry July 2007) were obtained from John Hunter Hospital pharmacy. CSL antivenoms are horse derived $\mathrm{F}\left(\mathrm{ab}^{\prime}\right)_{2}$ immunoglobulins raised against each of the five clinically important terrestrial snake groups in Australia Pseudonaja (Brown snake), Notechis (Tiger snake), Oxyuranus (Taipan), Pseudechis (Black snake) and Acanthophis (Death Adder). One unit (1U) of antivenom is defined as the amount that binds or neutralises $0.01 \mathrm{mg}$ of venom from the respective snake species. Expired CSL antivenoms have been shown to remain active past their stated expiry dates and are suitable for use in in vitro experiments (O'Leary et al., 2009).

\subsection{Chemicals and other reagents}

Fresh frozen plasma was purchased from the Australian Red Cross and aliquots of $10 \mathrm{ml}$ were thawed at $37{ }^{\circ} \mathrm{C}$. Calcium ( $50 \mu \mathrm{L} 0.4 \mathrm{M} \mathrm{CaCl}_{2}$ ) was added immediately prior to the assay. Tris Buffered Saline (TBS) is tris(hydroxymethyl)methylamine $25 \mathrm{mM}, \mathrm{NaCl}(137 \mathrm{mM}), \mathrm{KCl}$ (3.4 mM) adjusted to $\mathrm{pH} 7.4$ with $\mathrm{HCl}$. Innovin ${ }^{\circledR}$ (recombinant tissue factor) was obtained from Dade. Solutions ( $76 \mathrm{mg} / \mathrm{ml}$ ) were prepared according to the manufacturer's instructions, then diluted to $10 \%$ in TBS.

Anti-P. australis venom IgY was purchased from GenWay Biotech Inc (San Diego USA). Rabbit anti-N. scutatus venom IgG and rabbit anti-P. porphyriacus venom IgG were purchased from the Western Australian Institute of Medical Research and their preparation has been previously described in detail (Isbister et al., 2010a, b). For ELISA experiments, Greiner high-binding 96 well plates were used (\#655061). Carbonate buffer used for coating is $50 \mathrm{mM}, \mathrm{pH}$ 9.5. Antibodies were biotinylated using the Pierce EZ-Link Sulfo-NHS-LC-Biotin reagent. Washing solution is $0.02 \%$ Tween 20 in phosphate buffered saline (PBS). Blocking solution is $0.5 \%$ Bovine Serum Albumin in PBS. Streptavidin-horseradish peroxidase (HRP) was purchased from Millipore/Chemicon and tetramethylbenzidine (TMB) from Sigma. p-Bromophenacyl bromide (pBPB) was obtained from Sigma. All other chemicals used were of analytical grade.

\subsection{Clotting studies}

Clotting studies were performed using a turbidimetric assay described elsewhere (O'Leary and Isbister, 2010). In brief, procoagulant activities were tested by adding 1:1 serial dilutions of Pseudechis venom (starting at $1 \mu \mathrm{g}$ ) in $100 \mu \mathrm{l}$ TBS to wells of a 96-well microtitre plate. Clotting was triggered by adding $100 \mu \mathrm{L}$ of recalcified fresh frozen plasma, incubated at $37{ }^{\circ} \mathrm{C}$. Wells were mixed for $5 \mathrm{~s}$ and optical density at $340 \mathrm{~nm}$ at $37^{\circ} \mathrm{C}$ was recorded immediately and at $30 \mathrm{~s}$ intervals in a BioTek ELx808 plate reader. Clotting time was calculated based on previous definitions as the lag time before a 0.02 increase in optical density (OD) at $340 \mathrm{~nm}$ from the mean of the first two values (O'Leary and Isbister, 2010). Procoagulant activity of Pseudechis venoms was determined as a shortening of the clotting time compared to no venom addition.

Anticoagulant activity was measured in a similar way but recombinant tissue factor (Innovin; including synthetic 
A

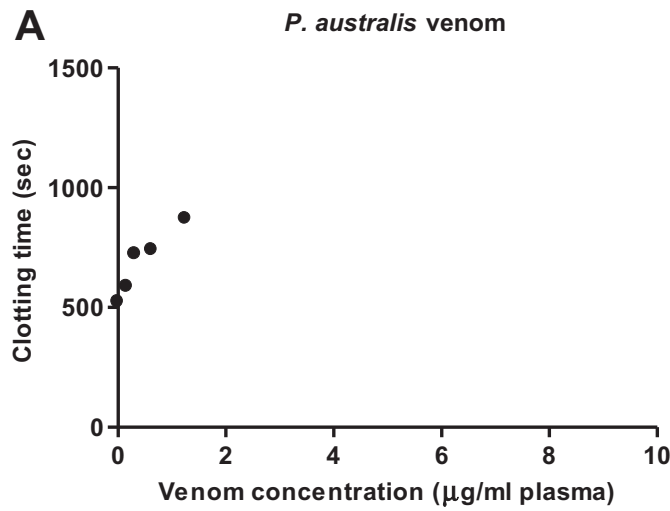

B

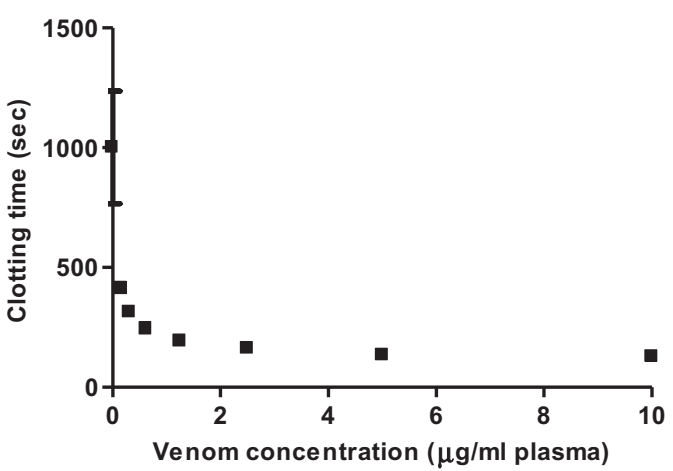

Fig. 1. Procoagulant effects of Pseudechis venoms. Clotting times for increasing concentrations of venom in the absence of another triggering agent showing the absence of procoagulant activity for $P$. australis venom (A) and the procoagulant activity of $P$. porphyriacus venom (B). Other Pseudechis venoms behaved as for $P$. australis venom, showing no procoagulant activity (data not shown).

phospholipids and calcium) was pre-mixed with Pseudechis venoms and used to trigger clot formation, which occurred in less than $30 \mathrm{~s}$ with Innovin alone. When venom was added an increase in the clotting time was then used as a measure of anticoagulant activity. This was done by adding 1:1 dilutions of Pseudechis venoms (starting at $50 \mathrm{ng}$ or $5 \mathrm{ng}$ ) and $380 \mu \mathrm{g}$ of Innovin in $100 \mu \mathrm{l}$ TBS to wells of 96well microtitre plate. Anticoagulant activity was defined as the venom concentration that caused a doubling of the Innovin induced clotting time from 22 to $44 \mathrm{~s}$. Procoagulant studies for $P$. porphyriacus and all anticoagulant clotting studies were done in triplicate and the mean value and standard error of the mean used.

For antivenom neutralisation studies $25 \mathrm{ng}$ of Pseudechis venom, $380 \mu \mathrm{g}$ Innovin and serial doubling dilutions of BISAV (starting at $45 \mathrm{mU}$ ) or TSAV (starting at $75 \mathrm{mU}$ ) in $150 \mu \mathrm{l}$ TBS were added to wells of a 96-well microtitre plate. Venom or antivenom concentrations were recorded as $\mathrm{ng} / \mathrm{ml}$ of plasma or $\mathrm{mU} / \mathrm{ml}$ of plasma respectively. The minimum inhibitory concentration of each antivenom was defined as the concentration required to completely inhibit anticoagulant activity (normalise clotting time back to less than $30 \mathrm{~s}$ ).

Neutralisation studies with monovalent rabbit antisnake IgG were carried out as above, beginning the 1:1 serial dilutions of either anti-P. porphyriacus or anti-N. scutatus IgG at $40 \mu \mathrm{g} /$ well, and with $P$. australis or $P$. porphyriacus venoms at $5 \mathrm{ng} / \mathrm{ml}$.

\subsection{Enzyme immunoassays}

A sandwich enzyme immunoassay was used to quantify known concentrations of each Pseudechis venom using antibodies to either $P$. porphyriacus, $P$. australis or N. scutatus venoms to detect the venoms to measure crossreactivity. For example, a range of concentrations of $P$. australis venom was put on a plate coated with anti-P. porphyriacus antibodies and then detected with anti-P. porphyriacus antibodies. Three 96-well microtitre plates were coated with $100 \mu \mathrm{l} /$ well of $3.75 \mu \mathrm{g} / \mathrm{ml}$ rabbit anti-P. porphyriacus $\operatorname{IgG}, 2.1 \mu \mathrm{g} / \mathrm{ml}$ rabbit anti-N. scutatus $\operatorname{IgG}$ or
$975 \mathrm{ng} / \mathrm{ml}$ anti-P. australis IgY in carbonate buffer for $1 \mathrm{~h}$ at room temperature and kept at $4{ }^{\circ} \mathrm{C}$ overnight. Plates were washed once and $300 \mu \mathrm{l}$ of blocking solution was added to each well. Plates were washed again and $100 \mu$ venom dilutions in triplicate were added as follows and left for $1 \mathrm{~h}$ at room temperature: 1:1 dilutions in blocking solution of standards ( $P$. porphyriacus, N. scutatus and $P$. australis venoms for each of the three plates respectively) from $2.5 \mathrm{ng} / \mathrm{ml}$ to $0.039 \mathrm{ng} / \mathrm{ml}$; and $1.25,0.63$ and $0.31 \mathrm{ng} / \mathrm{ml}$ of all other venoms. Plates were washed three times and $100 \mu \mathrm{l}$ biotinylated anti-P. porphyriacus rabbit IgG, anti-N. scutatus rabbit IgG or anti-P. australis IgY were added to the respective plates at an optimum titrated concentration. Plates were left for $1 \mathrm{~h}$ at room temperature, washed four times and $100 \mu \mathrm{l} /$ well of streptavidin-HRP $(1.5 \mu \mathrm{g} / \mathrm{ml})$ was added. Plates were washed four times and $100 \mu \mathrm{l} /$ well of TMB was added. Plates were left for up to $10 \mathrm{~min}$ for a colour change to appear before adding $50 \mu \mathrm{l} 1 \mathrm{M} \mathrm{H}_{2} \mathrm{SO}_{4}$. Plates were incubated for $1 \mathrm{~h}$ at room temperature before each wash stage and were read $20 \mathrm{~min}$ after acid addition at $450 \mathrm{~nm}$ in a BioTek ELx808 plate reader.

The percent cross-reactivity was calculated as the ratio of the measured concentration for the Pseudechis venom to the measured concentration for the venom corresponding to the antibodies on the plate (i.e. P. porphyriacus, P. australis or N. scutatus).

\section{5. $P L A_{2}$ assays}

$\mathrm{PLA}_{2}$ activities of Pseudechis venoms were measured using the PLA 2 assay kit (Cayman \# 765001). Venoms were diluted to $100 \mathrm{ng} / \mathrm{ml}$ in assay buffer. Venom (1 ng) +/$4.5 \mathrm{mU}$ BISAV, $0.75 \mathrm{mU}$ TSAV or $2 \mu \mathrm{g}$ anti-N. scutatus IgG in $10 \mu \mathrm{l}$ of assay buffer were added to separate wells of a 96well microtitre plate. Bee venom $\mathrm{PLA}_{2}$ (5-10 ng) or no venom in $10 \mu \mathrm{l}$ of assay buffer was added to separate wells as a positive control and background activity measurement respectively. CSL antivenom mixtures and anti-NsV were incubated with venoms at room temperature for 15 or 30 min respectively. DTNB $(10 \mu \mathrm{l})$ and assay buffer $(5 \mu \mathrm{l})$ were added to each well. Plates and diheptanoyl thio-PC 
A

P. porphyriacus
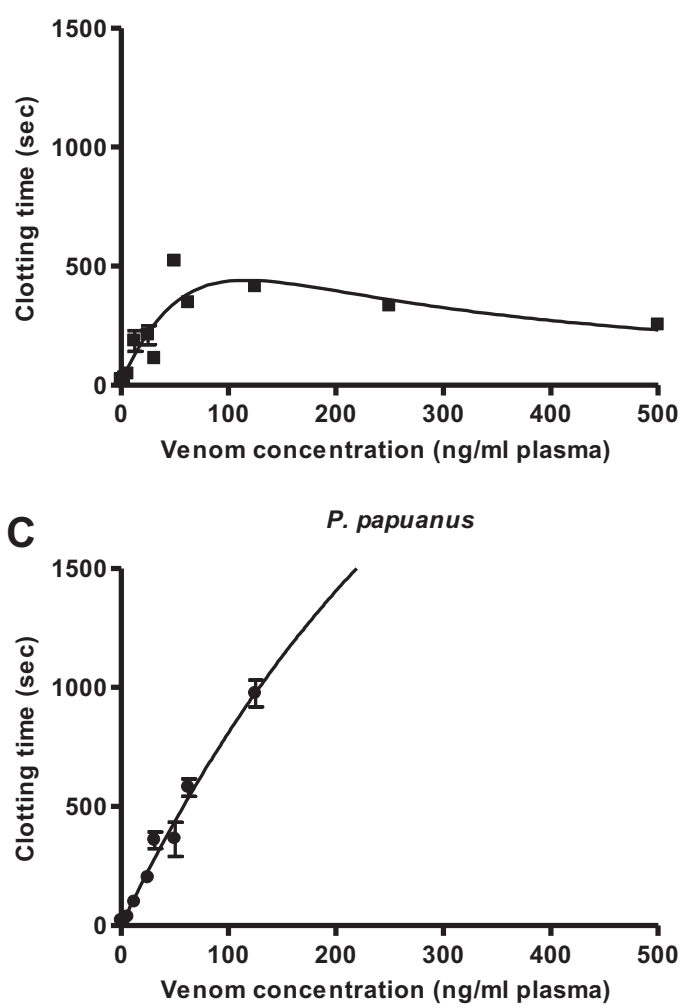

E

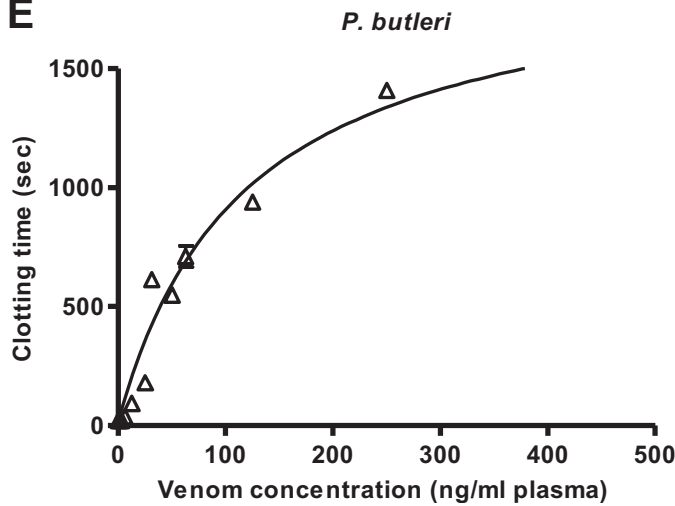

B

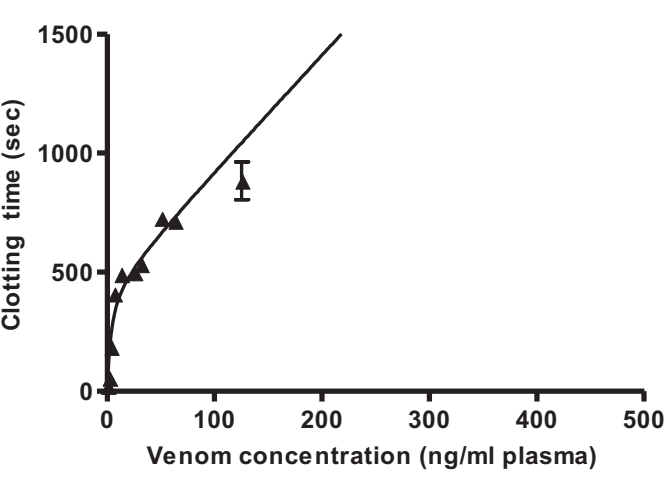

D

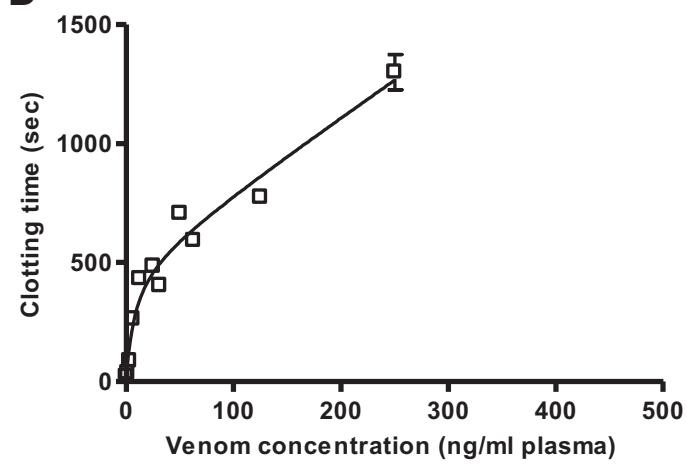

$\mathbf{F}$

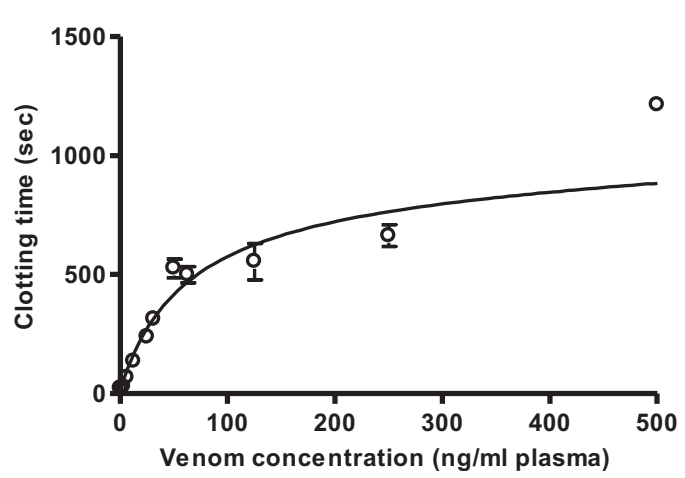

Fig. 2. Anticoagulant effects of Pseudechis venoms. Clotting times for increasing concentrations of venom in the presence of Innovin for P. porphyriacus, P. australis, P. butleri, P. colletti, P. guttatus and P. papuanus.

(substrate) were incubated separately at $37^{\circ} \mathrm{C}$ before being mixed for $2 \mathrm{~s}$. Samples were read immediately and at $30 \mathrm{~s}$ intervals for $10 \mathrm{~min}$ at $405 \mathrm{~nm}$ in a BioTek ELx808 plate reader. $\mathrm{PLA}_{2}$ activity is equivalent to the change in concentration of product which in turn is proportional to change in OD at $405 \mathrm{~nm} \mathrm{PLA}_{2}$ activity was therefore expressed as nmol of product $/ \mathrm{ml} / \mathrm{min} / \mathrm{ng}$ of venom.

\subsection{Treatment of venoms with $p B P B$}

Para-bromophenacyl bromide (pBPB) is a phospholipase inhibitor, which acts by blocking a histidine residue at the active site (Volwerk et al., 1974). pBPB was dissolved in ethanol and a portion added to water to give a concentration of $50 \mu \mathrm{g} / \mathrm{ml}$ in $0.1 \%$ ethanol. $100 \mu \mathrm{l}$ of this $(5 \mu \mathrm{g})$ was added to venom $(25 \mu \mathrm{g})$ in PBS $(400 \mu \mathrm{l})$ and the solutions allowed to stand for $2 \mathrm{~h}$ at room temperature. Control solutions were prepared at the same time without $\mathrm{pBPB}$, or without venom. These solutions were tested for PLA 2 and anticoagulant activity.

In an alternative procedure, a solution of $\mathrm{pBPB}$ in ethanol was prepared $(5 \mathrm{mg} / \mathrm{ml})$ and $20 \mu \mathrm{l}$ of this was added to solutions of control $P$. porphyriacus venom $(200 \mu \mathrm{g})$ in TBS $(2 \mathrm{ml})$. After $20 \mathrm{~h}$ at room temperature, excess pBPB was removed by dialysis (90 min in $200 \mathrm{ml}$ TBS). Control venom solutions were prepared by the same 

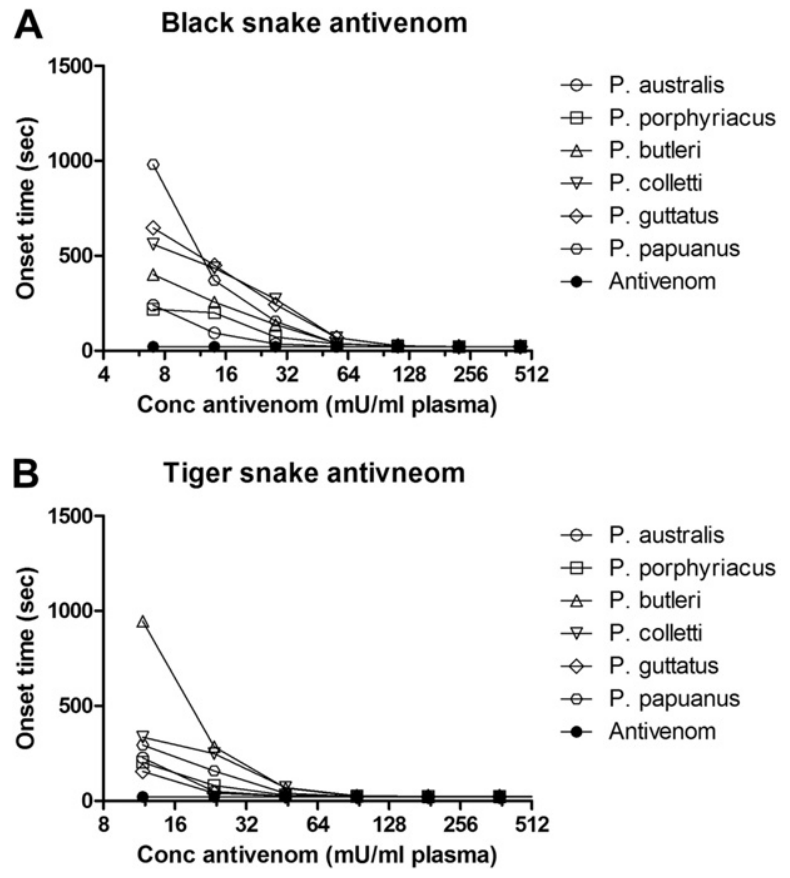

Fig. 3. Plots of Innovin triggered clotting times for all six Pseudechis venoms (250 ng/ml) versus increasing antivenom concentration when either BISAV (A) or TSAV (B) is premixed with the venom. The clotting time is returned to normal $(<30 \mathrm{~s})$ at higher antivenom concentrations.

procedure, without the addition of pBPB. These solutions were compared for coagulant and anticoagulant activity over a range of concentrations and PLA 2 activity.

\subsection{Data analysis}

Standard curves for ELISAs were calculated by nonlinear regression using GraphPad Prism 4.0 (GraphPad Software Inc., San Diego, CA, USA). Other venoms were compared to the standard to give a percentage equivalent concentration and therefore percentage immunological cross-reactivity.

Table 1

Minimum inhibitory concentration (MIC) of BISAV and TSAV and equivalent percentage of one vial of antivenom required to achieve this concentration in a human patient. The proportions (\%) of one vial are based on 18000U of BISAV and 3000U of TSAV being administered intravenously into a plasma volume of $3000 \mathrm{ml}$ giving $6 \mathrm{U} / \mathrm{ml}$ and $1 \mathrm{U} / \mathrm{ml}$ respectively.

\begin{tabular}{|c|c|c|c|c|}
\hline \multirow[t]{2}{*}{ Venom } & \multicolumn{2}{|l|}{ BISAV } & \multicolumn{2}{|l|}{ TSAV } \\
\hline & $\begin{array}{l}\mathrm{MIC}(\mathrm{mU} / \\
\mathrm{ml})^{\mathrm{a}}\end{array}$ & $\begin{array}{l}\text { Equivalent } \\
\% \text { of } 1 \text { vial }\end{array}$ & $\begin{array}{l}\mathrm{MIC}(\mathrm{mU} / \\
\mathrm{ml})^{\mathrm{a}}\end{array}$ & $\begin{array}{l}\text { Equivalent } \\
\% \text { of } 1 \text { vial }\end{array}$ \\
\hline P. porphyriacus & 113 & 2 & 94 & 10 \\
\hline P. australis & 56 & 1 & 47 & 5 \\
\hline P. butleri & 113 & 2 & 94 & 10 \\
\hline P. colletti & 113 & 2 & 94 & 10 \\
\hline P. guttatus & 113 & 2 & 47 & 5 \\
\hline P. papuanus & 113 & 2 & 94 & 10 \\
\hline
\end{tabular}

a These antivenom concentrations correspond to concentrations observed in envenomed patients.

\section{Results}

\subsection{Effects of black snake venoms on coagulation}

P. porphyriacus had procoagulant activity for venom concentrations greater than $100 \mathrm{ng} / \mathrm{ml}$. All other Pseudechis venoms showed no procoagulant activity even for venom concentrations of up to $10 \mu \mathrm{g} / \mathrm{ml}$ (Fig. 1). All Pseudechis venoms had anticoagulant activity which was concentration dependent and had a sigmoidal response with a saturation effect at higher concentrations for all Pseudechis venoms except $P$. porphyriacus venom (Fig. 2). The anticoagulant activities of $P$. porphyriacus, $P$. australis, $P$. butleri, $P$. colleti, $P$. guttatus and P. papuanus were 62.5, 12.5, 3.13, 6.25, 25 and $6.25 \mathrm{ng} / \mathrm{mL}$ of plasma, respectively. P. porphyriacus venom had a non-linear increase in clotting time until a peak anticoagulant effect at about $125 \mathrm{ng} / \mathrm{ml}$ of plasma. Above $125 \mathrm{ng} / \mathrm{ml}$ the clotting time decreased consistent with procoagulant activity in a concentration dependent manner.

\subsection{Effect of antivenom and rabbit IgG on venom activity}

Both BISAV and TSAV were able to completely inhibit the anticoagulant activity of $250 \mathrm{ng} / \mathrm{ml}$ of all black snake venoms (Fig. 3). The minimum inhibitory concentration of the two antivenoms for each venom was less than observed antivenom concentrations in patients and equivalent to less than $2 \%$ of a vial of BISAV and less than $10 \%$ of a vial of TSAV (Table 1). TSAV was able to neutralise the procoagulant effects of $P$. porphyriacus at a lower concentration of $2000 \mathrm{mU} / \mathrm{ml}$ compared to BISAV which required greater than $8000 \mathrm{mU} / \mathrm{ml}$. Rabbit anti-P. porphyriacus IgG and rabbit anti-N. scutatus IgG inhibited the anticoagulant activity of $P$. porphyriacus venom in a dose dependent manner at similar concentrations of IgG. Rabbit anti-N. scutatus IgG also inhibited the anticoagulant activity of $P$. australis venom.

\subsection{Immunological cross-reactivity}

All Pseudechis venoms cross-reacted with antibodies raised against P. porphyriacus, $P$. australis and $N$. scutatus to varying degrees (Table 2). P. australis and P. porphyriacus are the least cross-reactive venoms within the Pseudechis genera with other venoms showing intermediate cross reactivity. In comparison to $P$. australis venoms, P. colletti, $P$. guttatus and $P$. papuanus have very high immunological cross reactivity where as $P$. butleri and $P$. porphyriacus have decreasing cross reactivity to $P$. australis antibodies. All the Pseudechis venoms were between $9 \%$ and $20 \%$ cross reactive with antibodies raised against $N$. scutatus.

\subsection{Phospholipase activity}

All Pseudechis venoms had similar PLA 2 activity (nmol of product $/ \mathrm{ml} / \mathrm{min} / \mathrm{ng}$ ) with values of $9.3, P$. australis 18 , P. butleri, 9.5, P. colletti, 11.7, P. guttatus, 13.4, P. papuanus and 15.5 , P. porphyriacus. When venoms were preincubated with antivenoms, both BISAV and TSAV reduced PLA activity of the venoms to below $4 \%$ of that of venom alone (Fig. 4). However, anti-N. scutatus venom IgG only partially 
Table 2

Immunological cross reactivity of all six Pseudechis venoms, $N$. scutatus and $O$. scutellatus venoms with antibodies to $P$. porphyriacus, $P$. australis and N. scutatus.

\begin{tabular}{lccc}
\hline \multirow{2}{*}{ Venom } & \multicolumn{2}{c}{ Mean \% cross reactivity } \\
\cline { 2 - 4 } & P. porphyriacus & P. australis & N. scutatus \\
\hline P. australis & 18 & 100 & 20 \\
P. butleri & 21 & 46 & 13 \\
P. colletti & 56 & 95 & 18 \\
P. guttatus & 51 & 100 & 9 \\
P. papuanus & 33 & 100 & 14 \\
P. porphyriacus & 100 & 16 & 17 \\
N. scutatus & 9 & 0 & 98 \\
O. scutellatus & 0 & 0 & 7 \\
\hline
\end{tabular}

neutralised $\mathrm{PLA}_{2}$ activity with between 23 and $38 \%$ remaining compared to venom alone (Fig. 4). PLA 2 activity of $\mathrm{N}$. scutatus venom was completely neutralised by anti- $N$. scutatus venom IgG.

\subsection{Effect of $p B P B$ treatment on phospholipase and coagulant activity}

pBPB treatment completely inhibited PLA 2 activity of all Pseudechis venoms and also neutralised their anticoagulant activity (Fig. 5; data not shown). However, the procoagulant activity of $\mathrm{pBPB}$-treated $P$. porphyriacus venom was unaffected by pBPB treatment (Fig. 5).

\section{Discussion}

This study demonstrates that all Pseudechis venoms have in vitro anticoagulant effects which could be neutralised with antivenom concentrations easily achieved by the administration of less than one vial of BISAV or TSAV. In addition, the coagulant effects of $P$. porphyriacus were unique and showed both anticoagulant activity at lower concentrations typically seen in human envenoming and procoagulant activity for higher concentrations (Churchman et al., 2010). This explains some of the contradictory findings from previous in vitro studies (Chester and Crawford, 1982; Marshall and Herrmann, 1983; Tan and Ponnudurai, 1990) and clinical series of $P$. porphyriacus envenoming (Pearn et al., 2000). It was previously believed that $P$. porphyriacus venom only had procoagulant effects and caused only a mild silent coagulopathy (Chester and Crawford, 1982; Marshall and Herrmann, 1983; Tan and Ponnudurai, 1990; Pearn et al., 2000). The current study showed that procoagulant effects occur at venom concentrations in excess of those measured in human envenoming cases and this explains the absence of VICC seen clinically (Churchman et al., 2010). The fall in anticoagulant activity after the peak effect seen in Fig. 2 is explained by the procoagulant activity of the venom overcoming the anticoagulant effects at these venom concentrations. Further work is required to clarify this interaction. This dual procoagulant-anticoagulant effect has been demonstrated for Calloselasma rhodostoma and Agkristrodon contortix venoms before but no explanation for its existence has been offered (Dambisya et al., 1994).

An anticoagulant coagulopathy has now been reported in envenoming by $P$. porphyriacus (Churchman et al., 2010), P. australis (Campbell, 1984; Currie, 2004), P. colletti (Isbister et al., 2006) and P. papuanus (Lalloo et al., 1994), but was not evident in P. guttatus (Jansen et al., 2007) envenoming. However, the small number of cases does not rule out the

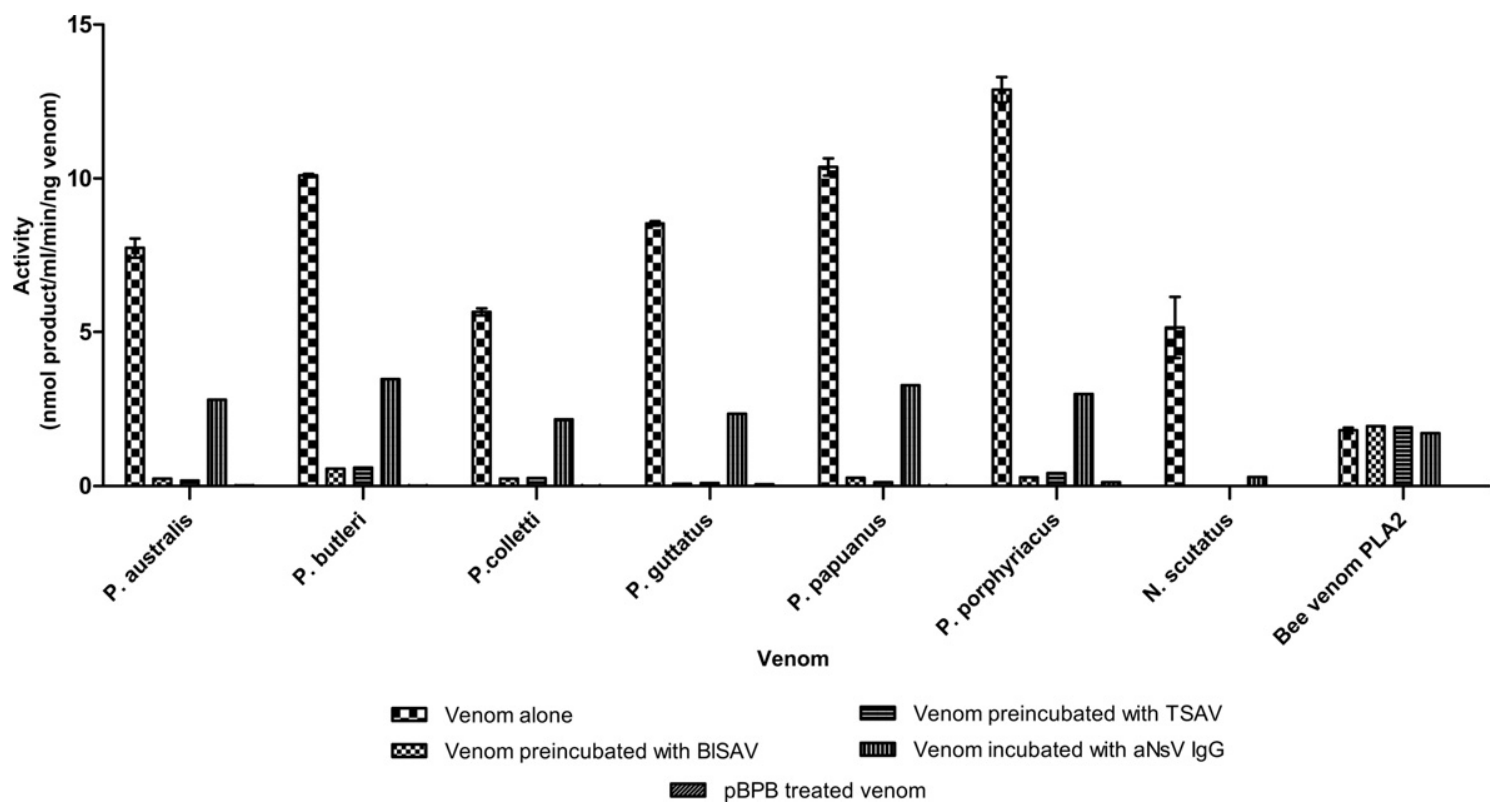

Fig. 4. The effect of BISAV (4.5mU), TSAV $(0.75 \mathrm{mU})$, rabbit anti-N. scutatus venom IgG antibodies (aNsV IgG; $2 \mu \mathrm{g})$ and p-BPB on the phospholipase activity of all six Pseudechis venoms. Results were not obtained for p-BPB treated $N$. scutatus venom, p-BPB treated bee venom PLA 2 and $N$. scutatus venom premixed with antivenom. 


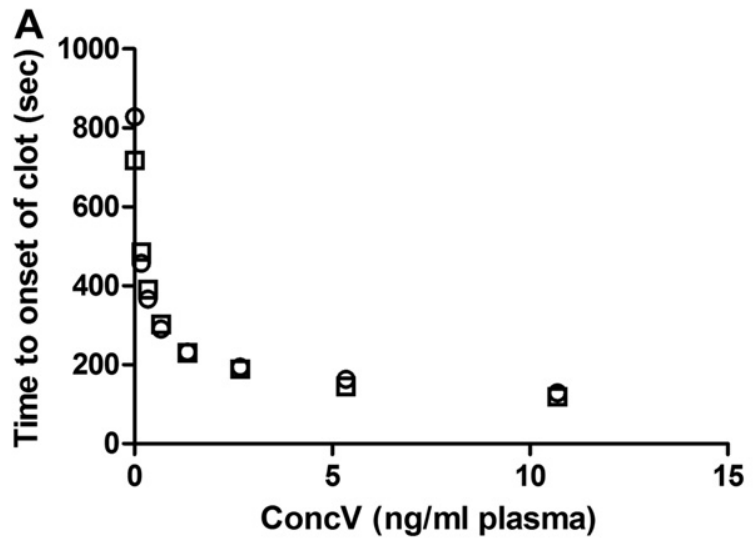

B

ㅁ $\mathrm{pBPB}$ treated venom
○ Control venom

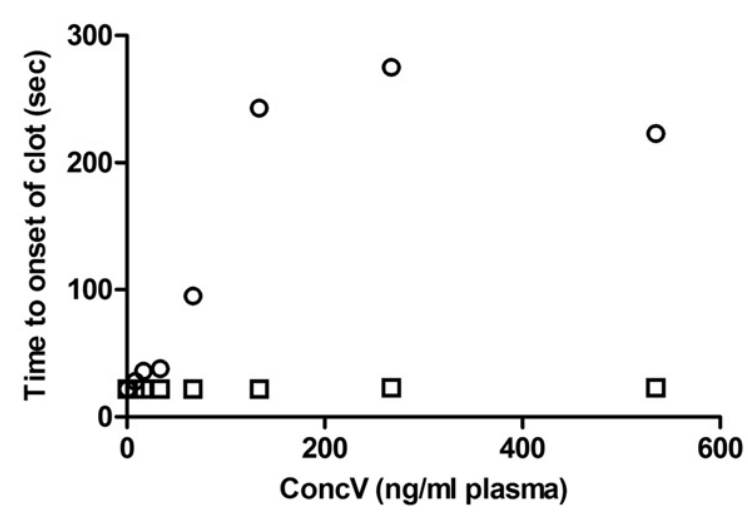

Fig. 5. The effect of pBPB treatment on the procoagulant (A) and anticoagulant (B) activity of $P$. porphyriacus venom.

possibility of a coagulopathy in the latter and there is potential for problems with standard laboratory assays detecting the anticoagulant coagulopathy which is likely the reason that it was not identified in $P$. porphyriacus envenoming earlier (Churchman et al., 2010).

The anticoagulant effects of all Pseudechis venoms at $250 \mathrm{ng} / \mathrm{ml}$ were completely neutralised by both BISAV and TSAV used at concentrations equivalent to far less than those likely to occur in patients administered one vial of antivenom (Table 2). Both antivenoms also neutralised $\mathrm{PLA}_{2}$ activity of all six Pseudechis venoms and have been previously shown to prevent but not reverse myotoxic effects of Pseudechis venoms (Ramasamy et al., 2004). Because myotoxicity and the anticoagulant coagulopathy are the major effects of Pseudechis envenoming it appears that both antivenoms are effective at neutralising the clinically relevant toxicity. Furthermore Pseudechis venom concentrations of $250 \mathrm{ng} / \mathrm{ml}$ rarely occur in human envenoming with median concentrations for $P$. porphyriacus and $P$. papuanus envenoming of $19 \mathrm{ng} / \mathrm{ml}$ (Churchman et al., 2010) and $39 \mathrm{ng} / \mathrm{ml}$ (Lalloo et al., 1994) respectively. Therefore one vial of antivenom is likely to be sufficient in human envenoming. This is supported by a recent study of
P. porphyriacus envenoming where one vial of TSAV bound all venom in vivo (Churchman et al., 2010).

$\mathrm{PLA}_{2}$ activity has been previously demonstrated in Pseudechis venoms (Ramasamy et al., 2004). The elimination of both anticoagulant and PLA 2 activity of Pseudechis venoms by $\mathrm{pBPB}$ suggests that the anticoagulant toxin is a $\mathrm{PLA}_{2}$ toxin which is consistent with other anticoagulant toxins (Kini, 2006). It is also likely that all Pseudechis venoms contain similar anticoagulant PLA 2 toxins as $\mathrm{PLA}_{2}$ activity was inhibited by both CSL antivenoms but further work is required to isolate the individual toxins and demonstrate this. The procoagulant activity in $P$. porphyriacus venom is likely to be due to a previously identified toxin that is similar but smaller than the prothrombin activators in other Australasian elapids (St Pierre et al., 2005). The procoagulant effect was only neutralised by antivenom and not pBPB treatment which is consistent with it being a separate toxin that is not a PLA2. Further work is required to confirm that the procoagulant activity is not due to a PLA 2 toxin.

Neutralisation of Pseudechis venoms by TSAV could be due to the current production methods of the commercial antivenom which mean that monovalent antivenoms are actually polyvalent so TSAV would contain antibodies raised against Pseudechis venoms (O'Leary and Isbister, 2009). However, the current study also demonstrated immunological and functional cross-reactivity between antibodies raised against $N$. scutatus and Pseudechis venoms. Rabbit anti-N. scutatus IgG was able to partially inhibit $\mathrm{PLA}_{2}$ activity of all Pseudechis venoms and completely inhibit anticoagulant activity of $P$. australis and $P$. porphyriacus venoms. This demonstrates a similarity between $\mathrm{PLA}_{2}$ enzymes with different toxicological properties from more distantly related elapid species since $N$. scutatus does not cause an anticoagulant coagulopathy. Immunological and functional cross-reactivity between components of venoms from different species and respective monovalent antibodies has been previously demonstrated for Pseudonaja textilis, O. scutellatus and N. scutatus venoms and may become important for future antivenom design (O'Leary et al., 2007; Isbister et al., 2010). This study provides further support for the development of toxin specific antivenom rather than species specific antivenom.

The effect of antivenom on the procoagulant effect of $P$. porphyriacus was unusual in that larger concentrations of BISAV were required to neutralise these effects than TSAV compared to similar concentrations for anticoagulant effects (Table 1). This may be because BISAV is raised against $P$. australis venom which does not contain a procoagulant toxin where as TSAV is raised against $N$. scutatus which contains the prothrombin activator Notecarin which has similar homology to the procoagulant toxin identified in P. porphyriacus (St Pierre et al. 2005).

Pseudechis venoms all show anticoagulant activity at concentrations similar to those seen in human envenoming cases. This effect is important in human envenoming after Pseudechis bites since anticoagulant coagulopathy occurs early in envenoming and appears to be rapidly reversed by antivenom (White, 2001; Isbister et al., 2006; Churchman et al., 2010). It therefore could be used as both an early indicator of envenoming and a clinical indicator of 
antivenom response. We have previously shown this for $P$. porphyriacus venom in patients but further work is required to demonstrate this for the other Pseudechis species (Churchman et al., 2010). Further to this, the anticoagulant toxin appears to be a PLA 2 enzyme that is inhibited by both BISAV and TSAV as well as anti-N. scutatus IgG, therefore demonstrating cross-reactivity between antibodies raised against venoms of unrelated snake species (Wagstaff et al., 2006; Wagstaff et al., 2009; Isbister et al., 2010).

\section{Funding}

JL was partly funded by a Wellcome Trust Student Elective Prize. The study was supported in part by NHMRC Project Grant ID490305. GKI is supported by an NHMRC Clinical Career Development Award ID605817.

\section{Ethical statement}

No ethics approval was required.

\section{Conflict of interest}

None.

\section{References}

Campbell, C.H., 1984. Myotoxic paralysis and hemolytic anemia due to king brown snake bite. Australian \& New Zealand Journal of Medicine 14 (2), 169.

Chester, A., Crawford, G.P., 1982. In vitro coagulant properties of venoms from Australian snakes. Toxicon 20 (2), 501-504.

Churchman, A., O’Leary, M., et al., 2010. Clinical effects of red-bellied black snake (Pseudechis porphyriacus) envenoming and correlation with venom concentrations: Australian snakebite project (ASP-11). Medical Journal of Australia 193 (11/12), 696-700.

Cogger, H., 2000. Reptiles and Amphibians of Australia. Reed Books Australia, Port Melbourne.

Currie, B.J., 2004. Snakebite in tropical Australia: a prospective study in the "top end" of the Northern Territory. Medical Journal of Australia $181(11-12)$, 693-697.

Dambisya, Y.M., Lee, T.-L., et al., 1994. Action of Calloselasma rhodostoma (Malayan pit viper) venom on human blood coagulation and fibrinolysis using computerized thromboelastography (CTEG). Toxicon 32 (12), 1619

Isbister, G.K., 2006. Snake bite: a current approach to management. Australian Prescriber 29 (5), 125-129.

Isbister, G.K., 2009. Procoagulant snake toxins: laboratory studies, diagnosis, and understanding snakebite coagulopathy. Seminars in Thrombosis \& Hemostasis 35 (1), 93-103.

Isbister, G.K., Hooper, M.R., et al., 2006. Collett's snake (Pseudechis colletti) envenoming in snake handlers. Qjm 99 (2), 109-115.

Isbister, G.K., O'Leary, M.A., et al., 2010a. Cross-neutralisation of Australian brown snake, Taipan and death adder venoms by monovalent antibodies. Vaccine 28 (3), 798-802.
Isbister, G.K., Scorgie, F.E., et al., 2010b. Factor deficiencies in venom induced consumption coagulopathy resulting from Australian elapid envenomation: Australian snakebite project (ASP-10). Journal of Thrombosis \& Haemostasis 8 (11), 2504-2513.

Jansen, M., McLeod, M., et al., 2007. Spotted black snake (Pseudechis guttatus) envenoming. Medical Journal of Australia 186 (1), 41-42.

Kamiguti, A.S., Laing, G.D., et al., 1994. Biological properties of the venom of the Papuan black snake (Pseudechis papuanus): presence of a phospholipase A2 platelet inhibitor. Toxicon 32 (8), 915-925.

Kini, R.M., 2006. Anticoagulant proteins from snake venoms: structure, function and mechanism. Biochemical Journal 397 (3), 377-387.

Laing, G.D., Kamiguti, A.S., et al., 1995. Characterisation of a purified phospholipase A2 from the venom of the Papuan black snake (Pseudechis papuanus). Biochimica et Biophysica Acta 1250 (2), 137-143.

Lalloo, D., Trevett, A., et al., 1994. Neurotoxicity and haemostatic disturbances in patients envenomed by the Papuan black snake (Pseudechis papuanus). Toxicon 32 (8), 927-936.

Lomonte, B., Angulo, Y., et al., 2003. An overview of lysine-49 phospholipase A2 myotoxins from crotalid snake venoms and their structural determinants of myotoxic action. Toxicon 42, 901-995.

Madaras, F., Smith, I., et al., 1983. Purification and characterisation of coagulation inhibitors from the King Brown venom [abstract]. Clinical \& Experimental Pharmacology \& Physiology 10, 490.

Marshall, L.R., Herrmann, R.P., 1983. Coagulant and anticoagulant actions of Australian snake venoms. Thrombosis \& Haemostasis 50 (3), 707-711.

O'Leary, M.A., Isbister, G.K., 2009. Commercial monovalent antivenoms in Australia are polyvalent. Toxicon 54 (2), 192.

O'Leary, M.A., Isbister, G.K., 2010. A turbidimetric assay for the measurement of clotting times of procoagulant venoms in plasma. Journal of Pharmacological \& Toxicological Methods 61 (1), 27-31.

O'Leary, M.A., Kornhauser, R.S., et al., 2009. An examination of the activity of expired and mistreated commercial Australian antivenoms. Transactions of the Royal Society of Tropical Medicine and Hygiene 103 (9), 937.

O'Leary, M.A., Schneider, J.J., et al., 2007. Cross-neutralisation of Australian brown and tiger snake venoms with commercial antivenoms: crossreactivity or antivenom mixtures? Toxicon 50 (2), 206.

Pearn, J., McGuire, B., et al., 2000. The envenomation syndrome caused by the Australian red-bellied Black Snake Pseudechis porphyriacus. Toxicon 38 (12), 1715-1729.

Ramasamy, S., Isbister, G.K., et al., 2004. The efficacy of two antivenoms against the in vitro myotoxic effects of black snake (Pseudechis) venoms in the chick biventer cervicis nerve-muscle preparation. Toxicon 44 (8), 837-845.

St Pierre, L., Masci, P., et al., 2005. Comparative analysis of prothrombin activators from the venom of Australian elapids. Molecular Biology and Evolution 22, 1853-1864.

Tan, N.-H., Ponnudurai, G., 1990. A comparative study of the biological properties of Australian elapid venoms. Comparative Biochemistry and Physiology Part C: Comparative Pharmacology 97 (1), 99.

Vines, A., 1978. Severe local reaction to bite of King Brown snake. Medical Journal of Australia 1 (12), 657.

Volwerk, J., Pieterson, W., et al., 1974. Histidine at the active site of phospholipase A2. Biochemistry 13 (7), 1446-1454.

Wagstaff, S., Laing, G., et al., 2006. Bioinformatics and multiepitope DNA immunization to design rational snake antivenom. PLoS Medicine 3, e184.

Wagstaff, S., Sanz, L., et al., 2009. Combined snake venomics and venom gland transcriptomic analysis of the ocellated carpet Viper, Echis ocellatus. Journal of Proteomics 71, 609-623.

White, J., 1998. "Envenoming and antivenom use in Australia. Toxicon 36 (11), 1483.

White, J., 2001. CSL Antivenom Handbook. CSL Ltd, Melbourne. 